\title{
In Memoriam Jaak Panksepp: Pioneer of Affective Neuroscience
}

Neuropsychopharmacology (2017) 42, 2470; doi:I0.1038/npp.20I7.168

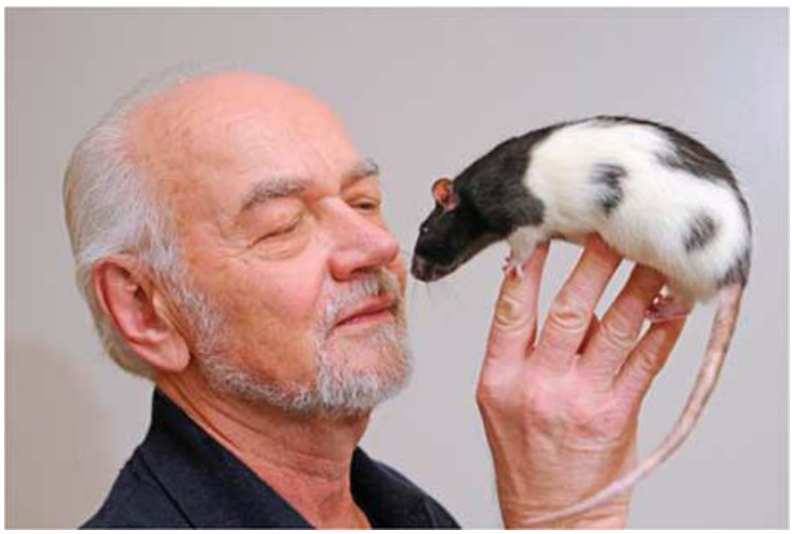

Born on 5 June 1942 in Tartu, Estonia, Dr Jaak Panksepp passed away on 18 April 2017 in Bowling Green, OH, at the age of 73 . He is survived by his wife, Anesa, and their children Jules, Antonia, and Ruth.

Jaak graduated with a BS in Psychology in 1965 from the University of Pittsburgh and received his Master of Science (1967) and Doctor of Philosophy (1969) degrees in Psychobiology/Neuroscience from the University of Massachusetts, Amherst. The title of his dissertation was The Neural Basis of Aggression. Upon receiving his $\mathrm{PhD}$, he received post-doctoral research fellowships from NSF and NIGMS to continue his studies at the University of Sussex in Brighton, England, followed by a NIMH post-doctoral fellowship at the Worcester Foundation for Experimental Biology, Shrewsbury, MA. Upon completion of his postdoctoral training, in 1972, he joined the faculty at Bowling Green State University as an Assistant Professor and within five years had been promoted to a full professor, followed by promotion to a Distinguished Research Professor of Psychobiology in 1988, which he continued as an emeritus faculty member since 1998. In 2001, he became the Head of Affective Neuroscience Research at the Chicago Institute for Neurosurgery and Neuroresearch and Falk Center for Molecular Therapeutics, and in 2006 became the Research Co-Director for the Hope for Depression Research Foundation. Also in 2006, he joined the faculty at Washington State University as the Baily Endowed Chair in Animal Well-Being
Science. In 2009, Jaak was accepted as member with the American College of Neuropsychopharmacology-a membership that he enjoyed greatly and was always very enthusiastic about. Having received a plethora of honors and accolades over the course of his career, one that Jaak was extremely proud of was his receipt of the Order of the White Star from the Government of Estonia, which is bestowed to provide recognition for services rendered to Estonia.

Jaak was a pioneer in the area of affective neuroscience at a time when many researchers discounted that animal emotions could be studied scientifically (or even existed). From his first publication in 1967, he published over 250 peer-reviewed articles, many of which received hundreds or thousands of citations. One of his most prolific and influential works was his textbook on Affective Neuroscience: The Foundations of Human and Animal Emotions, which was cited over seven thousand times. Jaak championed the use of experimental methods to study affective behavior in animals and the measurement of ultrasonic vocalizations in rats to assess their affective state. It was in this context that Jaak mentored me upon my arrival at Washington State University and for which I am eternally indebted. Jaak had a very direct and transparent communication style that made it very easy to ascertain where one stood scientifically with their questions of interest and how one's approach could be potentially improved-a style that I personally appreciated-he could always get right to the heart of the problem. Over the last couple of decades, Jaak became very well known for his investigations into the science of play from an affective context and was interviewed by numerous media outlets such as Discover Magazine and the Washington Post. His conceptual neurobiological organization of emotion had a profound influence on many generations of researchers, which is evidenced through his collaborations around the world and his pervasive influence on animal and human neuroscientific investigations.

Jaak, a friend and a mentor, will be missed by all that knew him, but his ideas will live on. He was dedicated to his family, his research and the mentoring of students and junior faculty, and had a way of opening new avenues of thought that will continue to influence generations of researchers and provide a translational evolutionary framework for the neuroscientific study of emotion.

Brendan M. Walker ${ }^{\star} 1$

${ }^{1}$ Washington State University, Pullman, WA, USA E-mail: b_walker@wsu.edu 